\title{
Damage evolution in wood:
} Synchrotron radiation microcomputed tomography ( $\mathrm{SR} \mu \mathrm{CT}$ ) as a complementary tool for interpreting acoustic emission (AE) behavior

\section{Journal Article}

\section{Author(s):}

Baensch, Franziska; Zauner, Michaela; Sanabria, Sergio J.; Sause, Markus G.R.; Pinzer, Bernd R.; Brunner, Andreas J.; Stampanoni, Marco; Niemz, Peter

Publication date:

2015-10-01

Permanent link:

https://doi.org/10.3929/ethz-b-000104853

Rights / license:

In Copyright - Non-Commercial Use Permitted

Originally published in:

Holzforschung 69(8), https://doi.org/10.1515/hf-2014-0152 
Franziska Baensch*, Michaela Zauner, Sergio J. Sanabria, Markus G.R. Sause, Bernd R. Pinzer, Andreas J. Brunner, Marco Stampanoni and Peter Niemz

\section{Damage evolution in wood: synchrotron radiation micro-computed tomography (SR $\mu \mathrm{CT})$ as a complementary tool for interpreting acoustic emission (AE) behavior}

\begin{abstract}
Tensile tests of miniature spruce wood specimens have been performed to investigate the damage evolution in wood at the microscopic scale. For this purpose, the samples were stepwise tensile loaded in the longitudinal (L) and radial (R) directions and the damage evolution was monitored in real-time by acoustic emission (AE) and synchrotron radiation micro-computed tomography $(\mathrm{SR} \mu \mathrm{CT})$. This combination is of outstanding benefit as $\mathrm{SR} \mu \mathrm{CT}$ monitoring provides an insight on the crack evolution and the final fracture at microscopic scale, whereas $\mathrm{AE}$ permits the detection of the associated accumulation and interaction of single damage events on all length scales with high time resolution. A significant drawback of the AE testing of wood has been overcome by means of calibrating the $\mathrm{AE}$ amplitudes with the underlying crack length development. Thus, a setup-dependent and wood species-dependent calibration value was estimated, which associates $1 \mu \mathrm{m}^{2}$ crack area generating of $0.0038 \mathrm{mV}$ in the detected $\mathrm{AE}$ amplitude. Furthermore, for both $\mathrm{L}$ and $\mathrm{R}$ specimens, AE signals were classified into two clusters by using a frequency-based approach of unsupervised pattern recognition. The shares of AE signals of both clusters correlate with the ratio of the relative crack area of
\end{abstract}

*Corresponding author: Franziska Baensch, ETH Zurich - Institute for Building Materials, Stefano-Franscini-Platz $3 \mathrm{CH}-8093$ Zürich, Zürich CH-8093, Switzerland, e-mail: fbaensch@hnee.de; and Eberswalde University for Sustainable Development - Wood Science and Technology, Eberswalde, Germany

Michaela Zauner, Sergio J. Sanabria and Peter Niemz: ETH Zurich Institute for Building Materials, Zürich, CH-8093, Switzerland Markus G.R. Sause: Institute for Physics, Experimental Physics II University of Augsburg, Augsburg, D-86135, Germany

Bernd R. Pinzer: Paul Scherrer Institute - SLS Tomcat, Villigen PSI, $\mathrm{CH}-5232$, Switzerland

Andreas J. Brunner: Empa, Swiss Federal Laboratories for Materials Science and Technology - Faculty for Mechanical Engineering, Dübendorf, $\mathrm{CH}-8600$, Switzerland

Marco Stampanoni: Paul Scherrer Institute - SLS Tomcat, Villigen PSI, CH-5232, Switzerland the interwall and transwall cracks gained from the fractographic analysis of SR $\mu$ CT scans.

Keywords: acoustic emission (AE), damage evolution, in situ monitoring, spruce, synchrotron radiation microcomputed tomography $(\mathrm{SR} \mu \mathrm{CT})$, tensile test, unsupervised pattern recognition (UPR)

DOI 10.1515/hf-2014-0152

Received May 20, 2014; accepted December 4, 2014; previously published online February 6, 2015

\section{Introduction}

The observation of the complex hierarchical interdependency of damage phenomena within the wooden structure is a key challenge (Frühmann et al. 2003; Saavedra Flores and Friswell 2013). For an improved understanding of the failure behavior, the acoustic emission (AE) measurement is a useful tool that enables a multiscale analysis of the damage progress with respect to load history in the whole specimen's volume. An additional advantage of the $\mathrm{AE}$ method is the high time resolution during the recording of defect generation. However, the interpretation of $\mathrm{AE}$ data is difficult concerning the signal's origin. In a previous study (Baensch et al. 2015), a new unsupervised pattern recognition (UPR) technique based on AE frequency features was adopted for wood. This algorithm, which had already been established for composite materials (Sause et al. 2012a,b), seeks for the numerically best partition of selected frequency features to identify the natural classes of AE signals.

A substantial and detailed interpretation of these $\mathrm{AE}$ clusters requires additional information. For this purpose, in situ X-ray tomography is suitable, as it allows a comprehensive 3D observation of microstructures (Cazaux et al. 1993; Stampanoni et al. 2006). Further, the feasibility of 
real-time studies on submacroscopic damage mechanisms by combining synchronous $\mathrm{AE}$ and tomographic monitoring has already been proven for several materials (Chotard et al. 2003; Elaqra et al. 2007), whereby an effective pixel length down to $15 \mu \mathrm{m}$ was reached. Another study was performed on metals yielding a spatial resolution of even 1.4 $\mu \mathrm{m}^{3}$ (Maire et al. 2007). For the investigation of the anatomical features of the wooden microstructure, the suitability of micro-computed tomography proves to be satisfactory, because a spatial resolution down to $1 \mu \mathrm{m}^{3}$ is feasible (Steppe et al. 2004; Trtik et al. 2007; Van den Bulcke et al. 2009). The microstructure of wood under different moisture loads has also been investigated by synchrotron radiation micro-computed tomography (SR $\mu \mathrm{CT}$ ) (Derome et al. 2011). Moreover, for a miniature wood specimen under bending load, Forsberg et al. (2008) showed the potential of the SR $\mu \mathrm{CT}$ method to evaluate the deformation at microscale by means of digital volume correlation.

In the present study, tensile tests of miniature spruce wood specimens will be performed to investigate the damage evolution in wood at the microscopic scale, which should be simultaneously monitored by AE and SR $\mu \mathrm{CT}$. The expectation is that the SR $\mu \mathrm{CT}$ results will provide complementary evidence for interpreting AE signal clusters already presented in a previous study by Baensch et al. (2015).

\section{Materials and methods}

The investigations were carried out on approximately 250 -year-old clear spruce wood [Picea abies (L.) Karst.] grown at $1000 \mathrm{~m}$ altitude in the canton of Grisons (Switzerland). The specimens were taken from the same wood stock whose mechanical properties were already described by Sonderegger et al. (2008) and Baensch et al. (2015).
Two specimens differing in fiber-load-angle were in focus. The radial (R) specimen was loaded in the $\mathrm{R}$ direction, and the longitudinal (L) specimen was loaded parallel to the grain (Figure 1a and b), whereby an L specimen was selected that only contained earlywood within the tested cross-section. The specimens were manufactured from blanks with dimensions of $30 \times 5.7 \times 2.3 \mathrm{~mm}^{3}$ (length $\times$ width $\times$ thickness). To ensure a defined crack initiation within the volume of interest (VOI), which can be monitored by both AE and SR $\mu \mathrm{CT}$ (Figure 1c), the specimens were tapered. The $\mathrm{L}$ specimen was taper shaped at all four sides, yielding a test cross-section of $1 \mathrm{~mm}^{2}$ (Figure $1 \mathrm{~b}$ ), whereas the R specimen had only a two-sided taper of approximately $4 \mathrm{~mm}^{2}$ test cross-section (Figure 1a), which could not be reduced further due to the fragile structure. The specimen geometry is in accordance with that tested by Baensch et al. (2015).

The SR $\mu$ CT trials were carried out at the TOMCAT beam line, a synchrotron beamline at the Paul Scherrer Institute in Villigen, Switzerland (Stampanoni et al. 2007). The tensile tests were performed with a loading device (load cell of $1 \mathrm{kN}$ ) for miniature specimens designed for implementation at the synchrotron beam line (Zauner et al. 2012). The $R$ specimen was loaded with a cross-head speed of $0.005 \mathrm{~mm} \mathrm{~s}^{-1}$ and the $\mathrm{L}$ specimen was loaded with $0.01 \mathrm{~mm} \mathrm{~s}^{-1}$ (Table 1). For load transmission, a plug system of three tubes was put over the specimen and fixed by a thread washer at the upper end (Figure 1c). This three-pieced plug system was needed to facilitate the mounting of AE sensors. The center tube was made of polyamide-imide (PAI 4203, Fa. Quadrant EPP Deutschland GmbH, Sinsheim, Germany). The duroplast PAI (165 MPa compression strength) was suitable for the $\mathrm{SR} \mu \mathrm{CT}$ monitoring of load tests on wood specimens because of its low absorption of the radiation.

To enhance the contrast of the X-ray images, a propagationbased phase-contrast reconstruction algorithm was applied (Paganin et al. 2002). The details on the SR $\mu$ CT monitoring parameters are presented in Table 2. The resolution was changed for both specimen types, allowing a field of view large enough to monitor the total VOI of the taper shape. Thus, for the L specimen, a digital resolution of $0.65 \mu \mathrm{m} \mathrm{px}^{-1}$ could be realized, whereas, in the case of the R specimen, a lower digital resolution of $1.62 \mu \mathrm{mpx}^{1}$ was reached.

$\mathrm{AE}$ monitoring was performed with an digital AE equipment (AMSY-6, Vallen Systeme GmbH, Icking, Germany). Two miniature piezoelectric sensors type M31 (Fuji Ceramics Corp. Shizuoka, Japan) with a coupling area of $3 \mathrm{~mm}$ diameter were mounted single sided

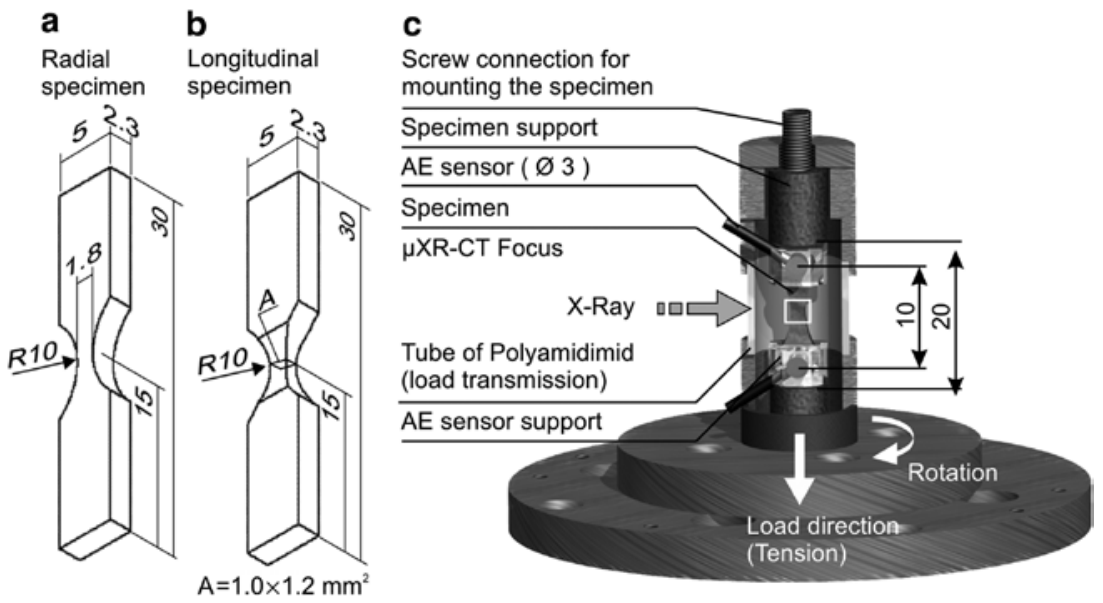

Figure 1 Specimen geometries and experimental design. 
Table 1 Characterization of the investigated spruce wood specimens.

\begin{tabular}{lrr}
\hline & \multicolumn{2}{c}{ Anatomical direction } \\
\cline { 2 - 3 } Parameter & $\mathbf{L}$ & $\mathbf{R}$ \\
\hline Density $\left(\mathrm{kg} \mathrm{m}^{-3}\right)$ & 349 & 342 \\
Moisture content (\%) & 8.3 & 7.8 \\
Cross-section $\left(\mathrm{mm}^{2}\right)$ & 1.20 & 4.15 \\
Speed of traverse $\left(\mathrm{mm} \mathrm{s}^{-1}\right)$ & 0.010 & 0.005 \\
Load steps $(-)$ & 8 & 2 \\
Test duration $(\mathrm{min})$ & 107 & 89 \\
Strength $(\mathrm{MPa})$ & 54.3 & 6.3 \\
SR $\mu$ CT resolution $\left(\mu \mathrm{m} \mathrm{px}^{-1}\right)$ & 0.65 & 1.62 \\
Thickness of two cell walls $\left(\mu \mathrm{m} \mathrm{px}^{-1}\right)$ & $5.2 \pm 1.5$ & $8.1 \pm 1.1$ \\
Acoustic velocity $\left(\mathrm{m} \mathrm{s}^{-1}\right)$ & 6000 & 2200 \\
\hline
\end{tabular}

${ }^{a}$ Sonderegger et al. (2008).

Table 2 Acquisition settings for SR $\mu \mathrm{CT}$ monitoring.

\begin{tabular}{lr}
\hline Energy of radiation & $\begin{array}{r}20 \mathrm{keV} \\
\text { Mode }\end{array}$ \\
Scintigram size; CCD camera & $\begin{array}{r}\text { Phase contrast } \\
2048 \times 2048 \mathrm{px}\end{array}$ \\
Rotation & $180^{\circ}$ in $0.12^{\circ} \mathrm{steps}$ \\
Projections & 1501 \\
Dark field projections & 32 \\
White field projections & 150 \\
Recording time of one Scan & $6 \mathrm{~min}$ \\
Monitoring L specimens (UPLAP010x) & \\
Field of view, digital resolution & $1.43 \times 1.43 \mathrm{~mm}^{2}, 0.65 \mu \mathrm{m} \mathrm{px}^{-1}$ \\
Monitoring R specimen (UPLAPO4x) $^{\mathrm{a}}$ & \\
Field of view, digital resolution & $3.58 \times 3.58 \mathrm{~mm}^{2}, 1.62 \times \mathrm{m} \mathrm{px}^{-1}$ \\
\hline
\end{tabular}

abjectives.

on the surface of the specimen (Figure 1c). The sensor coupling was achieved by silicone-free vacuum grease (Pöllath J.P. Labortechnik, Bamberg, Germany). AE sensors were sensitive to the frequency range of $300-800 \mathrm{kHz}$. The frequency range of the preamplifiers (AEP3, gain of $34 \mathrm{~dB}$ into $50 \Omega$, Vallen Systeme GmbH, Icking, Germany) was limited to the range from 30 to $960 \mathrm{kHz}$. Moreover, guard sensors (SE 150-M, Dunegan Engineering Co., Inc. Midland,
Table 3 Acquisition of AE waveform detection and settings of frequency spectra calculation.

\begin{tabular}{lr}
\hline Threshold setting & $32.1 \mathrm{~dB}_{\mathrm{AE}}(\approx 0.04 \mathrm{mV})$ \\
Rearm time & $1 \mathrm{~ms}$ \\
Sampling rate & $10 \mathrm{MHz}$ \\
Signal duration & $409.6 \mu \mathrm{s}, 18 \mu \mathrm{s}$ pre-trigger included \\
Signal evaluation & First signal of AE event; 1D localization \\
FFT of waveform & \\
Extraction window & First 256 samples of the waveform \\
in time domain & $0-25.6 \mu \mathrm{s}(18 \mu$ s pre-trigger excluded $)$ \\
Window function & Hamming window of $256 \mathrm{samples}$ \\
Frequency spectra & $0-1200 \mathrm{kHz}$ \\
\hline
\end{tabular}

USA) were mounted onto the testing device and on the mounting table at the beam line.

For AE analysis, only the first signal of an AE event detected by both sensors (maximum distance of $10 \mathrm{~mm}$ ) was evaluated by means of 1D localization (Kurz et al. 2008). AE signals were windowed with a Hamming window function (Table 3), and the selected frequency features were extracted from the frequency spectra. For the UPR algorithm, nine features in total (Table 4) were chosen as input, namely, the peak frequency (PF), the center of gravity frequency (CGF), weighted peak frequency (WPF), and six partial power (PP) levels (Sause et al. 2012a).

Before each test, the specimens were preloaded to $<20 \%$ of the ultimate stress and an initial SR $\mu \mathrm{CT}$ of the intact structure was recorded. The tensile tests were performed stepwise by stopping the traverse at predetermined positions, which were preliminarily defined with respect to the predicted $\mathrm{AE}$ occurrence. Specifically, in pre-tests (Baensch et al. 2015), the AE onset was evaluated by means of the applied traverse displacement. Before and after each load step, the quality of the AE sensor coupling was checked by autocalibration (in the course of which, each sensor served subsequently as an emitter and a sensor). When the displacement ceased, the load immediately decreased, indicating the relaxation processes of the wood. To minimize the risk of recording artifacts (structural movement) within the tomograms due to relaxation, an idle time of 1-2 min was allowed before starting the SR $\mu \mathrm{CT}$ scan, which was also monitored by $\mathrm{AE}$. However, performing the SR $\mu \mathrm{CT}$ scan might have a destructive impact on the tiny, wooden test cross-section due to relaxation processes during the time the traverse is arrested. For this reason, only selected SR $\mu$ CT scans were performed. Thus, the tests imply a

Table 4 AE frequency features used to perform the UPR.

\begin{tabular}{|c|c|c|c|}
\hline Feature & Abbreviation & \multicolumn{2}{|l|}{ Definition } \\
\hline Amplitude (mV) & A & \multicolumn{2}{|c|}{ Measured AE amplitude (mV) } \\
\hline Peak frequency & PF & \multicolumn{2}{|c|}{$\begin{array}{l}\text { Frequency of maximum magnitude in frequency spectrum } \\
\int f \cdot \tilde{U}(f) d f\end{array}$} \\
\hline Center of gravity frequency & CGF & \multicolumn{2}{|c|}{$\int \tilde{U}(f) d f$} \\
\hline Weighted peak frequency & WPF & \multicolumn{2}{|l|}{$\begin{array}{l}\sqrt{f_{\mathrm{PF}} \cdot f_{\mathrm{CGF}}} \\
\int_{f}^{f_{2}} \tilde{U}^{2}(f) d f\end{array}$} \\
\hline Partial power & PP & $\frac{f_{1}}{\int_{f_{\text {stant }}}^{f_{\text {end }}} \tilde{U}^{2}(f) d f}$ & $\begin{array}{l}\text { PP1: } 0-200 \mathrm{kHz}, \text { PP2: } 200-400 \mathrm{kHz}, \mathrm{PP} 3: 400-600 \mathrm{kHz}, \\
\text { PP4: } 600-800 \mathrm{kHz}, \mathrm{PP} 5: 800-1000 \mathrm{kHz}, \mathrm{PP} 6: 1000-1200 \mathrm{kHz}\end{array}$ \\
\hline
\end{tabular}


sequence of test stages comprising one or more loading steps, which are completed by one SR $\mu \mathrm{CT}$ scan. The tests were continued up to the ultimate failure of the specimens. AE and SR $\mu \mathrm{CT}$ data were synchronized by the load signal output of the testing device.

\section{Results and discussion}

\section{UPR}

For each specimen, the UPR technique yielded the numerically best separation of the detected AE into two clusters (Figure 2). These clusters (Figure 2, black circles) are in good agreement with those from the pre-investigation (without SR $\mu \mathrm{CT}$ ) by Baensch et al. (2015) (Figure 2 , gray squares); thus, the validity of the tests is proven. One cluster (A) comprises AE events of a relatively high share of low-frequency components, expressed by an average WPF of approximately $350 \mathrm{kHz}$. In contrast, the other cluster (B) contains AE events of a relatively high

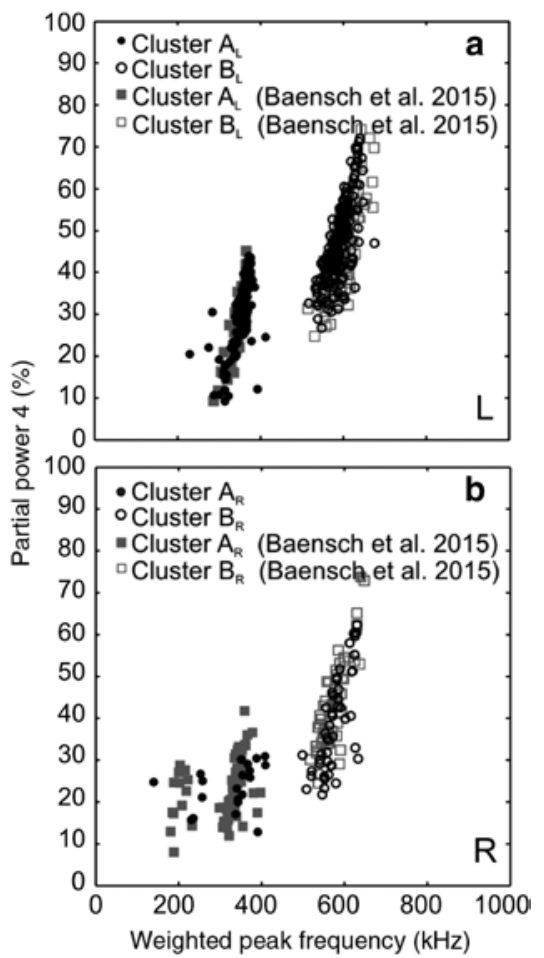

Figure 2 Clustering of AE signals yields the two clusters A (filled symbols) and B (unfilled symbols).

PP4 versus WPF (Table 4) are presented for AE signals detected during tensile tests on spruce specimens loaded in the (a) $L$ and (b) $\mathrm{R}$ directions. The reproducibility of the clusters is demonstrated by comparing the seven pre-trial results in the laboratory (gray squares) with the specimens tested at the SR $\mu \mathrm{CT}$ beamline (black circles). share of high-frequency components, which is characterized by an average WPF of approximately $575 \mathrm{kHz}$. A first working hypothesis to explain this AE behavior assumed that the A clusters indicated slow crack growths (e.g., cell separation mechanisms), whereas the B clusters signified brittle crack growths due to cell wall cracks (Baensch et al. 2015).

\section{L specimen}

During four test stages (I-IV), a total of eight load steps were applied to the $\mathrm{L}$ specimen until its ultimate failure (Figure 3). AE and SR $\mu \mathrm{CT}$ monitoring gained complete data sets for the test stages I to III (Figure 3a-c), whereas an SR $\mu$ CT scan of the fractured specimen after the last test stage IV (Figure 3d) yielded insufficient quality for reconstruction on account of the artifacts that distorted the tomograms due to the movement of the specimens. The cuboid in Figure $4 \mathrm{a}$ represents the volume $\left(650 \times 650 \times 650 \mu \mathrm{m}^{3}\right)$ including all damages detected by $\mathrm{SR} \mu \mathrm{CT}$ until the test stage III. In total, the observed cracks affected approximately 140 tracheids, which is equivalent to $10 \%$ of the tracheids within the entire VOI of the specimen.

During the first load step (Figure 3a), only AE events of cluster $B_{L}$ were generated. However, in light of the pre-investigations consistent with the current results (Baensch et al. 2015), the cluster type matching the AE onset is rather random. In the test stage II (Figure 3b), the traverse was displaced four times to yield a sufficient stress application for $\mathrm{AE}$ generation. Because no $\mathrm{AE}$ was detected during the first three steps, an SR $\mu$ CT scan was not performed. However, AE was detected during relaxation after the fourth traverse displacement in the test stage II, whereby cluster $B_{L}$ already yielded $A E$ amplitudes more than $3 \mathrm{mV}$ (Table 5). During the test stage III (sixth load step) and the subsequent relaxation (Figure 3c), cluster $B_{L}$ yielded the maximum $\mathrm{AE}$ amplitude of $8.4 \mathrm{mV}$ for the whole test, whereas cluster $A_{L}$ only generated $A E$ amplitudes $<4.1 \mathrm{mV}$ (Table 5). During the last two load steps in the test stage IV (Figure 3d; Table 5, steps 7 and 8), the intention was to increase the load application until the ultimate failure of the L specimen was achieved. For this reason, an SR $\mu$ CT scan was omitted after the seventh load step. For both load steps 7 and 8, the generated AE showed a high number of signals in both clusters with a wide range of $\mathrm{AE}$ amplitudes.

Although no cracks were observed after the first load step (I), the reconstructions after reloading the specimen (II) revealed significant damages (Figure 5). As the crack 

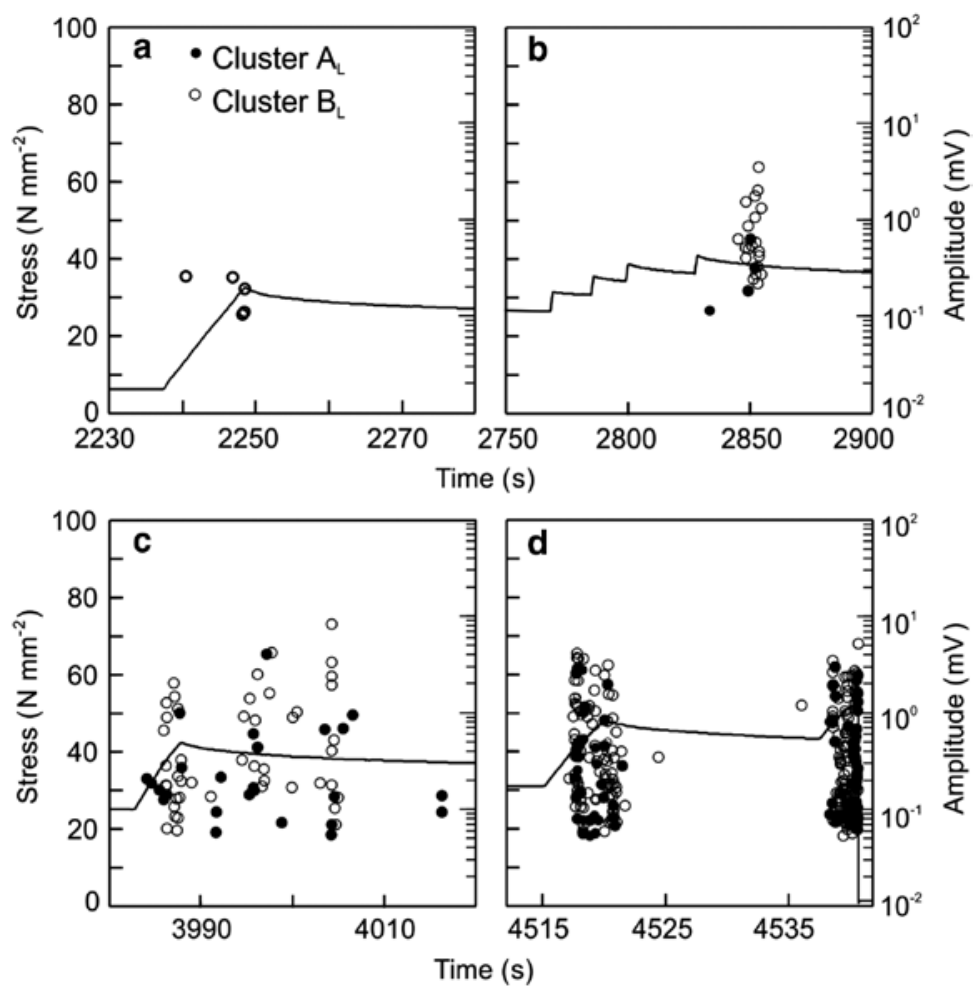

Figure 3 Tensile test on the L specimen: (a) test stage I, (b) test stage II, (c) test stage III, and (d) test stage IV with the ultimate failure (load step 8).

Stress and $A E$ signal amplitude vs. test duration. The two $A E$ signal clusters $A_{L}$ and $B_{L}$ are separated in the plots.
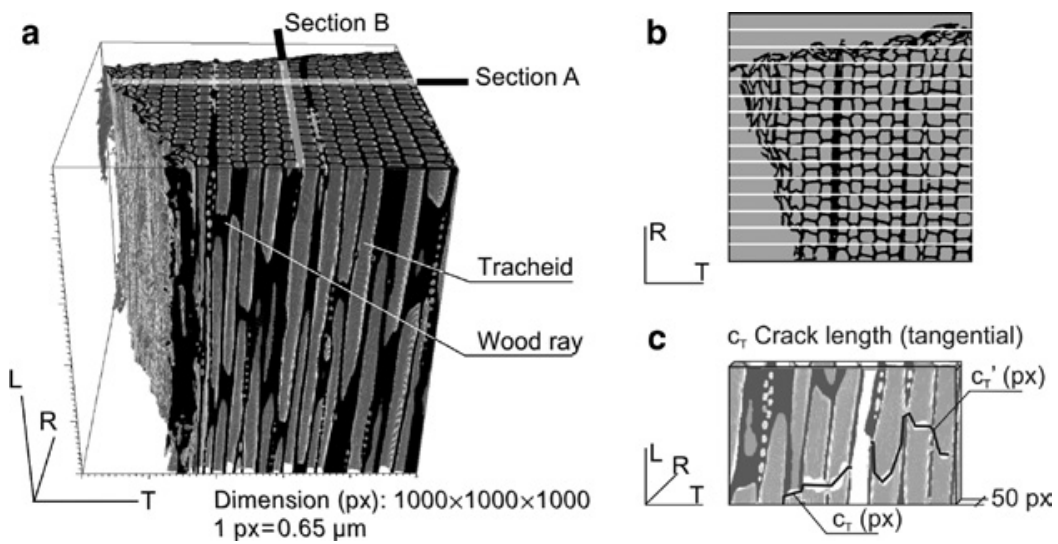

\section{Figure 4}

(a) Initial state of the $L$ tested specimen. This cubic section includes the state of crack after the load steps 1-3. Dimensions: $650 \times 650 \times 650 \mu \mathrm{m}^{3}$. Resolution of the reconstruction: $1 \mathrm{px}=0.65 \mu \mathrm{m}$. Sections A and B are shown in detail in Figure 5 . (b) For the crack length measurements, the cube is cut into 15 sections of 50 px thickness in the $R$ direction. (c) Crack length $c_{T}$ is measured along the cell walls in the LT plane for each of these 15 sections. Analogously, the crack length $\left(c_{R}\right)$ is determined. Based on both measurements, the average crack length $\overline{\mathrm{C}}$ is estimated.

is only visible in the surrounding cell wall, 3D volume subsets visualize the cell walls rather than single slice images. Thus, with respect to the average tracheid dimensions in the radial-tangential (RT) plane, the selected volume (Figure 4a) was cut along the $\mathrm{R}$ direction into
15 sections of $50 \mathrm{px}$ thickness $(32.5 \mu \mathrm{m})$ corresponding to the white lines marked in the RT plane in Figure 4b. Additionally, this subdivision into 15 sections was repeated along the tangential $(\mathrm{T})$ direction. The diameter of one tracheid $(27 \pm 3.7 \mu \mathrm{m})$ is smaller than the section's thickness 
Table 5 AE parameters of the loading steps for the $L$ and $R$ specimens.

\begin{tabular}{llrrrrr}
\hline & & & & \multicolumn{2}{c}{ AE amplitude of clusters A/B } \\
\cline { 5 - 7 } Specimen & Test stage & Load step & N (-) & Min (mV) & Max (mV) & Cumulative (mV) \\
\hline L & I & 1 & $0 / 5$ & $-/ 0.10$ & $-/ 0.26$ & $-/ 0.92$ \\
& II & $2-5$ & $5 / 19$ & $0.12 / 0.22$ & $0.64 / 3.56$ & $1.60 / 17.41$ \\
& III & 6 & $25 / 46$ & $0.05 / 0.06$ & $4.09 / 8.37$ & $11.00 / 42.57$ \\
& IV & 7 & $35 / 88$ & $0.07 / 0.05$ & $2.99 / 4.19$ & $22.25 / 67.14$ \\
& & 8 & $58 / 96$ & $0.07 / 0.05$ & $3.06 / 4.19$ & $27.59 / 66.48$ \\
R & 1 & $3 / 7$ & $0.06 / 0.09$ & $4.44 / 15.40$ & $4.57 / 20.41$ \\
& I & 2 & $17 / 41$ & $0.04 / 0.04$ & $52.27 / 35.86$ & $156.03 / 102.86$ \\
\hline
\end{tabular}

$N$, number of $A E$ events of the clusters $A / B$.
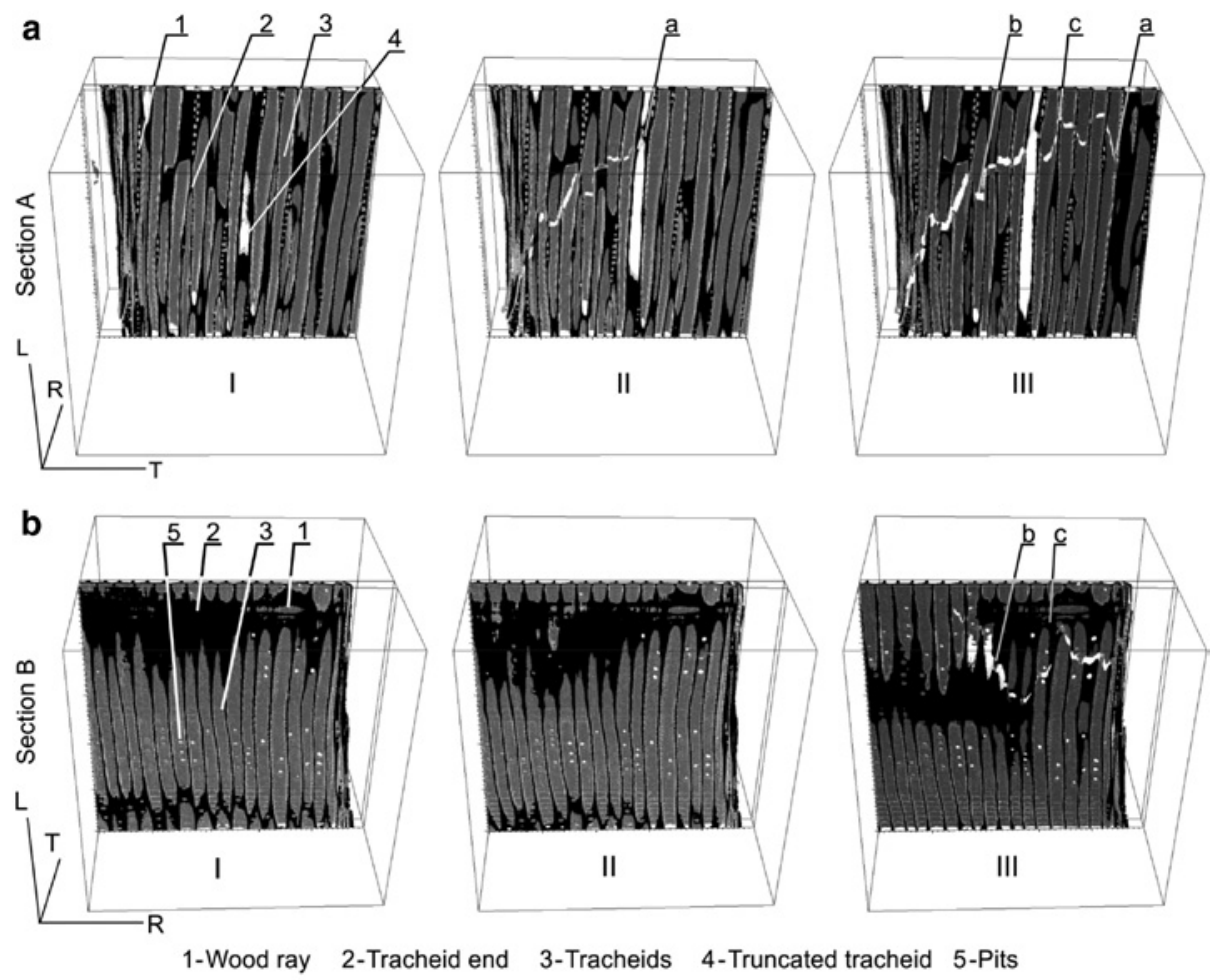

3-Tracheids 4 -Truncated tracheid 5-Pits

Dimension: $650 \mu \mathrm{m} \times 650 \mu \mathrm{m} \times 33 \mu \mathrm{m}$

Figure 5 Crack growths through the microscopic structure of the $L$ stressed specimen.

The cube represents the part of the specimen involving the whole crack evolution detected after load steps 2 and 3. (a) In section A, the crack growth is tracked in the LT plane. (b) In section B, the crack growth is tracked in the LR plane. The dimensions of sections A and B are $650 \times 650 \times 32.5 \mu \mathrm{m}^{3}$.

(32.5 $\mu \mathrm{m})$; therefore, the focus was only on one boundary containing cell walls of the two connected tracheids within the sections.

For sections A and B (Figure 4a), the initial state and the states of the crack after test stages II and III are presented in Figure 5. After the test stage II, the LT plane in section A already shows cracks crossing the tracheid cell wall boundaries (Figure 5a), which indicates transwall cracks as well as cracks within the middle lamella. The identified crack tip (Figure 5a, detail a) propagated further in the test stage III with larger and stepped displacements (Figure 5a, detail c) in the L direction. Moreover, the crack path avoids passing through the wood rays. The LR plane in section $B$ (Figure $5 b$ ) shows no damage in the test stage II, whereas the crack path in stage III (Figure 5b, details $\mathrm{b}$ and $\mathrm{c}$ ) also switches its propagation along the $\mathrm{L}$ direction. Hence, it seems that interwall cracks are of more relevance during the test stage III than in the earlier 
stage. This additionally coincides with the ratio of the signal numbers attributed to clusters $A_{L}$ and $B_{L}$, changing from 5:19 after the test stage II to 25:46 after the stage III (Table 5).

The crack at three different stages (I-III) was recorded by both $\mathrm{AE}$ and SR $\mu \mathrm{CT}$, and a calibration between the results of both methods was attempted. For this purpose, the $\mathrm{AE}$ amplitude was taken as a measure of damage magnitude. This approach is probably closest to the amplitude of the elastic wave that is proportional to the newly formed crack area (Radon and Pollock 1972; Lysak 1996; Sause 2010). Thus, the crack area (square micrometer of cell wall matter) and the corresponding cumulative AE amplitudes after each test stage II and III were compared (Table 6). The crack length in both states was measured within the $15 \mathrm{SR} \mu \mathrm{CT}$ sections along the $\mathrm{R}$ direction as well as along the $\mathrm{T}$ direction (Figure 4c). The crack length is measured within the tracheid cell wall volume containing both cell walls of two adjacent tracheids. The average crack length $\overline{\mathrm{C}}$ was estimated from the measured crack length, once in the $\mathrm{R}$ direction $\mathrm{C}_{\mathrm{R}}$ and a second time in the $\mathrm{T}$ direction $\mathrm{c}_{\mathrm{T}}$ (Figure 4c) for the stages II and III (Table 6). For the L specimen, the averaged double cell wall thickness $t_{\mathrm{cw}}$ is of 5.2 $\mu \mathrm{m}$ (Table 1). Hence, the averaged crack area $\overline{\mathrm{S}}$ (Table 6) is calculated based on the averaged crack length $\bar{c}$ and on the double cell wall thickness $t_{\mathrm{cW}}$ [Equation (1)].

$$
\overline{\mathrm{S}}=0.65 \frac{\mu \mathrm{m}}{\mathrm{px}} \times \overline{\mathrm{c}}(\mathrm{px}) \times \mathrm{t}_{\mathrm{cw}}(\mu \mathrm{m})
$$

The crack size in the ultimate failed state is unknown; thus, the crack area after the test stage III (19547 $\left.\mu \mathrm{m}^{2}\right)$ is defined as $100 \%$ (Table 6, III). The corresponding AE amplitude of $73.5 \mathrm{mV}$ cumulated for stages I to III is equally defined as $100 \%$. With respect to the crack size at the test stage III, the crack area measured after the test stage II is 30\% (Table 6). Although no damages were found within the sample reconstruction of the SR $\mu$ CT scan after the test stage I (possibly due to relaxation and crack closing processes), the $\mathrm{AE}$ detected there indicates initial pre-damages of the later crack. As a result, the AE amplitudes of the test stages I and II are summed up, also yielding 30\% of the total cumulative AE amplitude. By this, the

Table 6 Correlation between crack growth $\bar{c}$ and cumulative $A E$ amplitudes $A$ for the $L$ specimen.

\begin{tabular}{lrrrrrr}
\hline State & $\mathbf{c}_{\mathrm{R}}(\mathrm{px})$ & $\mathbf{c}_{\mathrm{T}}(\mathrm{px})$ & $\overline{\mathbf{c}}(\mathrm{px})$ & $\overline{\mathbf{S}}\left(\mu \mathrm{m}^{2}\right)$ & $\boldsymbol{\Sigma} \mathbf{A}(\mathrm{mV})$ & Correlation (\%) \\
\hline I & 0 & 0 & 0 & 0 & 0.92 & \\
II & 1470 & 2088 & 1780 & 6016 & 19.02 & $=30$ \\
III & 5095 & 6472 & 5783 & 19547 & 73.50 & 100 \\
\hline
\end{tabular}

cumulative AE amplitude is found to behave proportionally to the area of the crack (Lysak 1996). Based on this, a scale factor $b$ was approximated by the ratio of the cumulative amplitude A $(73.5 \mathrm{mV})$ to the averaged crack area $\overline{\mathrm{S}}$ $\left(19547 \mu \mathrm{m}^{2}\right)$ at the test stage III [Equation (2)].

$$
\mathrm{b}=\frac{\sum \mathrm{A}}{\sum \overline{\mathrm{S}}}=0.0038 \frac{\mathrm{mV}}{\mu \mathrm{m}^{2}}
$$

However, the amplitude of AE events is setup dependent; therefore, SR $\mu \mathrm{CT}$ is required to calibrate the coefficient b for crack size measurements. For the tests presented here, a crack area of $1 \mu \mathrm{m}^{2}$ is associated to approximately $0.0038 \mathrm{mV}$ in the detected $\mathrm{AE}$ amplitude [Equation (2)]. This correlation allows an estimation of the length scale of the damage events detected in AE. Consequently, the threshold setting of $0.04 \mathrm{mV}$ might enable detecting damage events that are too small for observation within the tomograms. The correlating crack area of approximately $10.5 \mu \mathrm{m}^{2}$ (whereas the averaged double cell wall thickness is $5.2 \mu \mathrm{m}$ ) implies a crack length of $2 \mu \mathrm{m}$, which falls beyond the effective resolution of the $\mathrm{SR} \mu \mathrm{CT}$ measurements. The same applies for the maximum AE amplitude measured during the first load step (Table 6, I). During the ultimate failure, the maximum $\mathrm{AE}$ amplitude of $8.4 \mathrm{mV}$ was generated in cluster $B_{L}$ (Table 5), whereby the resulting crack length $\overline{\mathrm{C}}$ of approximately $424 \mu \mathrm{m}$ consistently correlates with half the edge length of the specimen's test cross-sections (Table 1).

Nevertheless, the correlation value of $0.0038 \mathrm{mV}_{\mu \mathrm{m}}^{-2}$ has to be treated with caution, as it assumes homogeneous material properties. Thus, a differentiation of the cracking components is lacking, although their Young's modulus has a main impact on the measured AE amplitude (Scruby 1985). For instance, the Young's modulus of lignin in the middle lamellae ( $3 \mathrm{GPa}$; Cousin 1978) is smaller by a factor of about 10 than that of the cell wall $(25 \mathrm{GPa}$; Eder et al. 2009), and this is the reason why cracks in the middle lamellae of $1 \mu \mathrm{m}^{2}$ should yield AE amplitudes lower than $0.0038 \mathrm{mV}$. A direct and unambiguous correlation is not feasible between the cumulative $\mathrm{AE}$ amplitudes generated by each cluster and the attributed crack types because the crack's origin cell wall layers are difficult to track within the $\mathrm{SR} \mu \mathrm{CT}$ reconstructions.

\section{R specimen}

The R specimen was tested in two test stages. During the first load step (Figure 6a), $10 \mathrm{AE}$ events were recorded, which already revealed a significant range of $\mathrm{AE}$ signal amplitudes (0.06-15.4 mV; Table 5). However, no structural 


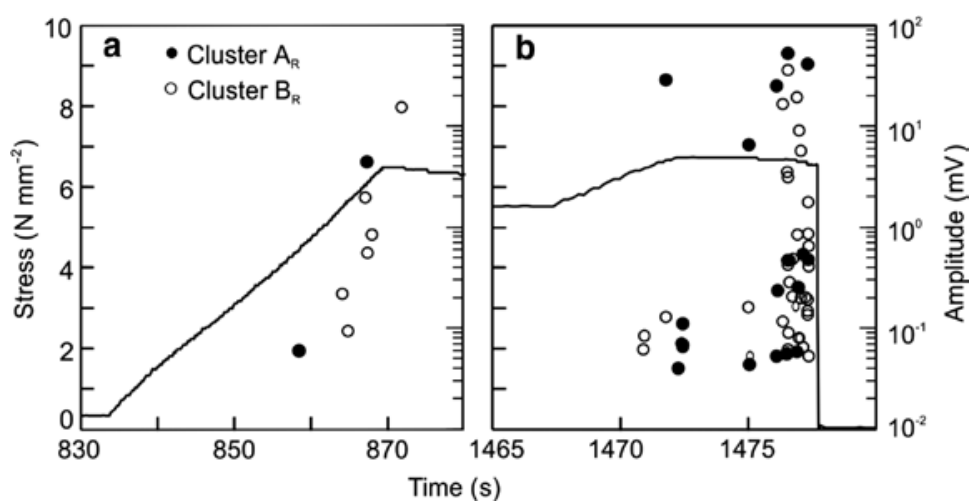

Figure 6 Tensile test of the R specimen: (a) test stage I and (b) test stage II, including the ultimate failure. Stress and AE signal amplitude vs. test duration. The two $A E$ signal clusters $A_{R}$ and $B_{R}$ are distinguished.

changes and damages were observed within the corresponding SR $\mu$ CT scan. The second loading reached the maximum stress of $6.7 \mathrm{MPa}$, whereas the ultimate failure of the R specimen occurred during the subsequent relaxation process, a few seconds after the traverse had been stopped (Figure 6b). During the ultimate failure, AE events of both $A_{R}$ and $B_{R}$ clusters yielded amplitudes above $10 \mathrm{mV}$ (Table 5). The damage analysis is supported only by the SR $\mu \mathrm{CT}$ scan of the failed state; thus, the whole fracture surface was analyzed (i.e., particularly the broken specimen's bottom half). The obtained results are exemplarily presented by means of the selected detail C (Figure 7). Detail $\mathrm{C}$ has dimensions of $650 \times 650 \times 650 \mu \mathrm{m}^{3}$ and thus represents $10 \%$ of the total fracture zone, which is located within the earlywood zone, clearly identifiable by comparing the initial state (Figure 8a) and the failed state (Figure 8b). A fractographic analysis of the fracture zone differentiates between transwall cracks and the peeling of

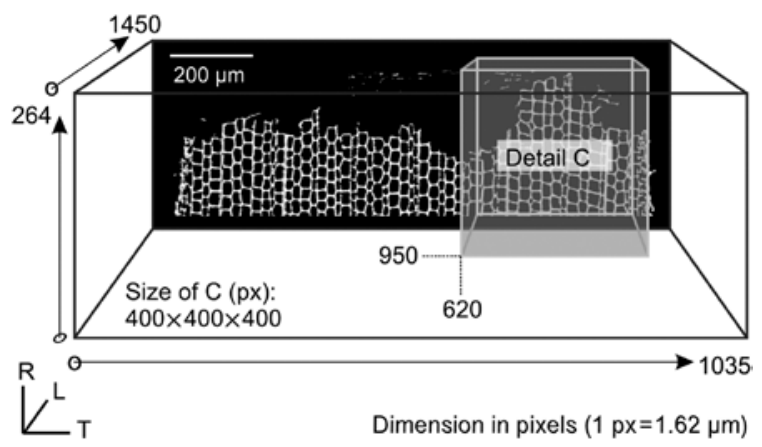

Figure 7 Dimension of the fracture zone of the spruce wood specimen tensile loaded in the $\mathrm{R}$ direction is represented by the black cube.

The back side of the cube shows the fracture path through the RT plane. Exemplarily, the results are presented for the selected detail C. The position and dimension $\left(650 \times 650 \times 650 \mu \mathrm{m}^{3}\right)$ are represented by the smaller gray cube. Resolution of the reconstruction from SR $\mu C T$ monitoring: $1 \mathrm{px}=1.62 \mu \mathrm{m}$. the tracheids by interwall cracks within the middle lamellae or possibly by intrawall cracks within the primary cell wall (cell separation phenomena). The procedure from this analysis performed for the whole fracture zone is demonstrated by detail C in Figure 9a.

To provide a quantitative assessment of the contribution ratio of both fracture types, the fracture surface was subdivided into units. Each of these units is limited in size to one tracheid in the $\mathrm{T}$ direction and $80 \mu \mathrm{m}$ (50 px) in the L direction; see the definition in Figure 9a. A projection map of the damaged surface in the LT plane was obtained, which indicates the relative positions of tracheids and wood rays and further distinguishes the units characterized by transwall cracks or cell separation (Figure 9a). Approximately $70 \%$ of the total fracture surface shows cell wall cracks. Overall, 100 wood rays and 50 tracheids are affected, and each of the tracheids shows both damage types. This observation is in agreement with the study by Ashby et al. (1985), who predicted the occurrence of both cell wall cracks and cell separation phenomena for a ratio of the raw density to the cell wall density $\left(1500 \mathrm{~kg} \mathrm{~m}^{-3}\right)$ beyond 0.2 , as is the case for the spruce wood tested here. The impact of the wood rays' mechanical performance on the crack formation through the walls of the adjacent tracheids becomes obvious, because all parts of those tracheids that completely enclose one wood ray show a similar damage type (Figure 9a). For an improved visualization of this linkage in the fracture formation (Figure 9b), the intact wood rays were segmented from the reconstruction of the initial state (black) and finally were superimposed onto the reconstruction of the failed state (gray). For the section in Figure 9b, the failure within the earlywood implies three wood rays a to c. The failure in the vicinity of both wood rays a and b occurred close to the latewood zone, and they are assumed to have induced strong reinforcing 

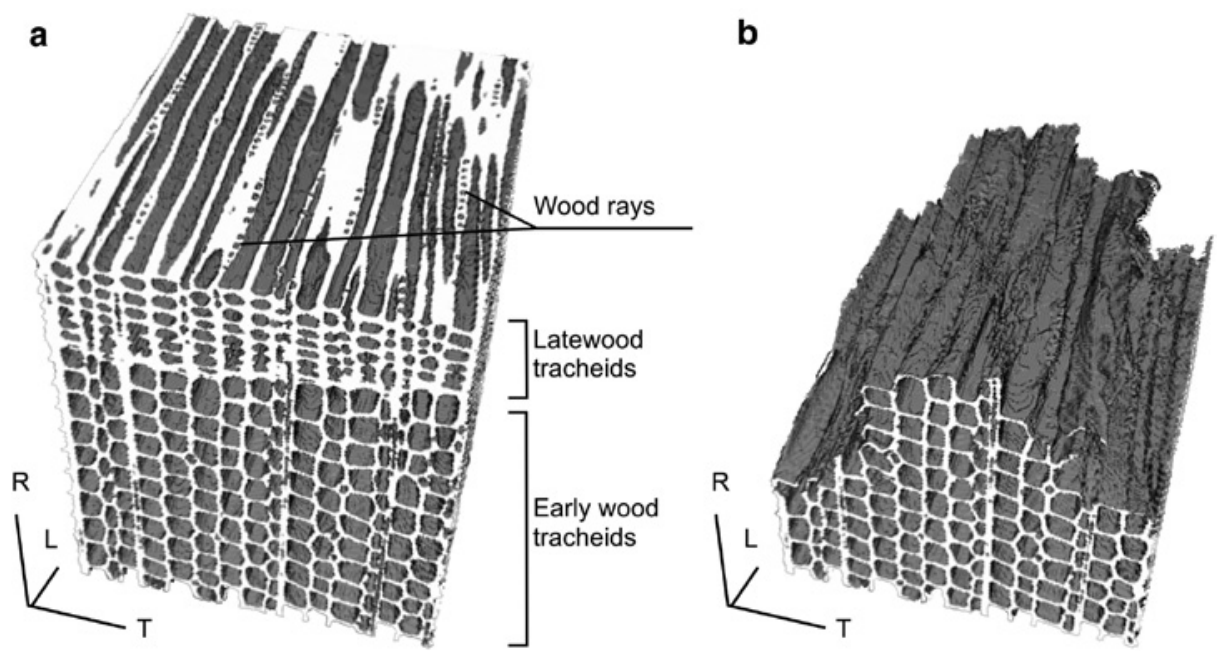

Figure 8 Spruce wood specimen tensile stressed in the R direction. Detail C $\left(650 \times 650 \times 650 \mu \mathrm{m}^{3}\right)$ at initial state (a) and failed state (b).

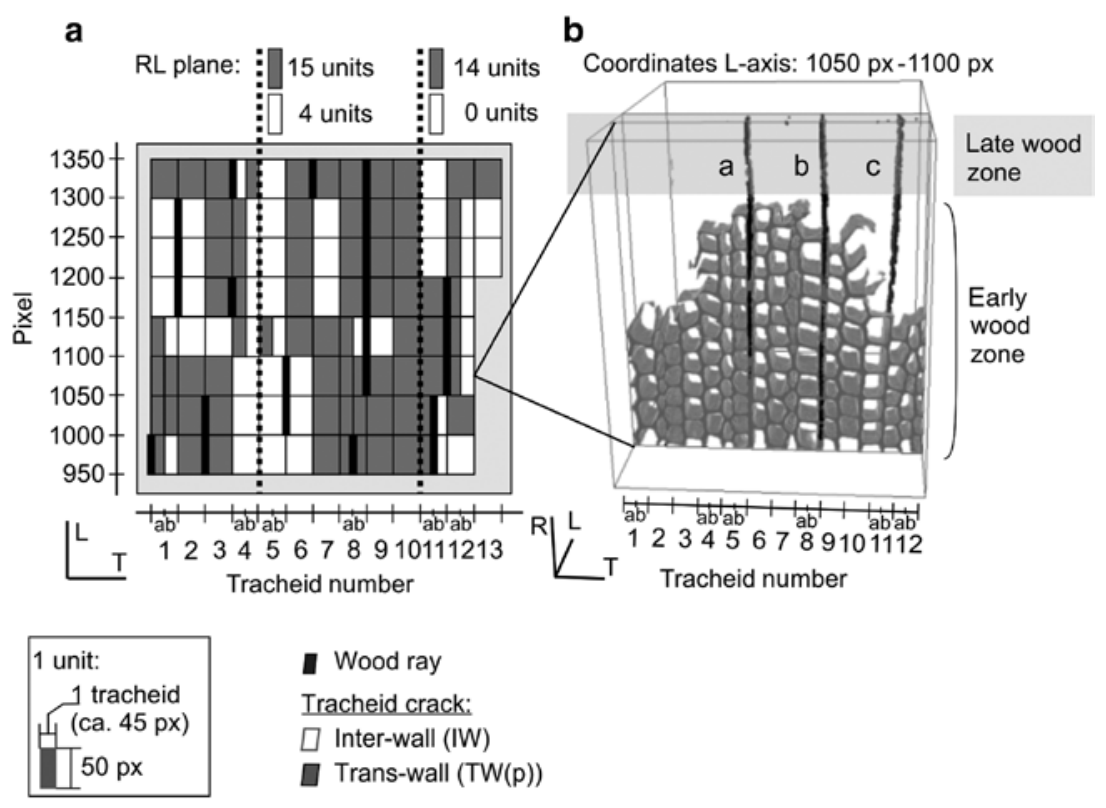

Figure 9 Fractographic analysis.

(a) Fracture surface of detail C presented as a 2D projection pattern (LT plane). For the fractographic analysis, the surface is divided into units. In the L direction, the length of one unit is 50 px $(\sim 80 \mu \mathrm{m})$; in the T direction, the size of one unit is due to one tracheid. Cell wall cracks and cell separation are differentiated in the TL plane. In the RL plane, the complex shear fractures include 29 units of cell wall cracks and 4 units of cell separation. (b) Section of the fracture zone from the detail C ( $L$ axis: $1050-1100$ px). For the visualization of the wood rays' influence on damage development, the intact wood rays segmented at the initial state (dark colored) are superimposed on the reconstruction of the ultimate failure (gray). For orientation, the latewood zone is highlighted. Wood rays a and b failed close to the latewood zone. The weak point of wood ray c, located deeper within the earlywood zone, led to tensile shear failure in RL plane.

effects on the adjacent earlywood tissue. In contrast, the weak point of the wood ray c was located deeper inside the earlywood zone. The failure of that wood ray induced a pullout mechanism, yielding a complex tensile shear fracture of the adjacent tracheids in the first row and even in the second row (Figure 9b, tracheids 9 and 10). The mechanical performance of wood rays and their position relative to each other affect the magnitude of the damage events (Reiterer et al. 2002) and therefore influence the $\mathrm{AE}$ amplitude during loading the tissue in $\mathrm{R}$ direction.

The scale factor $\mathrm{b}$ [Equation (2)] was applied to $\mathrm{AE}$ signals detected during the first load application of the $R$ specimen, for which a maximum $\mathrm{AE}$ amplitude of $15 \mathrm{mV}$ $\left(\approx 3950 \mu \mathrm{m}^{2}\right)$ was monitored, whereas the damage was 
not detected in the SR $\mu$ CT scans. Taking into account the double cell wall thickness of $8 \mu \mathrm{m}$ (Table 1), the correlated averaged crack length $\overline{\mathrm{c}}$ [Equation (2)] of approximately $490 \mu \mathrm{m}\left(\approx 305 \mathrm{px}\right.$; resolution of $\left.1.62 \mu \mathrm{m} \mathrm{px}^{-1}\right)$ is physically possible, particularly because this AE event of cluster $B_{R}$ is assumed to be cell wall damage. If the crack would not have affected the cell wall of two adjacent tracheids and would occur only within the cell wall of one single tracheid, it would not be detectable within the SR $\mu$ CT scan. Another explanation could be the possibility that the crack closes during the relaxation process before the $\mathrm{SR} \mu \mathrm{CT}$ scan is performed. The ultimate failure generated maximum AE amplitudes of $36 \mathrm{mV}$ in cluster $B_{R}$ (Table 5), correlating with an averaged crack length $\overline{\mathrm{C}}$ of approximately $1180 \mu \mathrm{m}$, which is more or less half the edge length of the specimen's test cross-section (Figure 1a; Table 1).

Moreover, a correlation between fiber breakage and the number of detected AE events can be assumed, which is also usually the case in composite materials (Harris et al. 1972). Based on this, the ratio of the relative crack area of the cell wall crack (67\%) and cell separation (33\%) estimated from SR $\mu \mathrm{CT}$ also might be reflected by the relative number of detected $\mathrm{AE}$ events due to cluster $\mathrm{B}_{\mathrm{R}}(70 \%)$ and cluster $A_{R}(30 \%)$ (Table 5).

\section{Conclusion}

Tensile tests on miniature spruce specimens, $\mathrm{R}$ and $\mathrm{L}$ loaded under tension, were monitored by $\mathrm{AE}$ and simultaneously by SR $\mu \mathrm{CT}$. This combination is very useful because the SR $\mu \mathrm{CT}$ monitoring provides insight on the microscopic structure of tested specimens under initial, crack evolution, and final fracture development. AE is a supplementary data source, which makes possible to detect the associated crack formation and propagation in the spatial domain, which results from the accumulation and interaction of single damage events.

The 3D SR $\mu$ CT monitoring yields the following main observations at the microscopic level: the crack path usually avoids crossing wood rays, which are the weak points within the wood structure when loading in the $\mathrm{L}$ direction. For tensile loading in the $\mathrm{R}$ direction, the main impact of the reinforcing wood rays on the fracture pattern shows similar damage types observed for those tracheids that completely enclose one wood ray. Each single tracheid within the fracture zone shows both transwall and interwall cracks.

An approximate correlation between the crack size from SR $\mu$ CT scan and the crack formation detected by $\mathrm{AE}$ was obtained: a crack area of $1 \mu \mathrm{m}^{2}$ was associated to approximately $0.0038 \mathrm{mV}$ in the detected setup-dependent and wood species-dependent AE amplitude. Depending on the threshold setting of $0.04 \mathrm{mV}$, the AE method turned out to be sensitive to minimum defect sizes of $10.5 \mu \mathrm{m}^{2}$, which scales with the tracheid cell wall's thickness.

Two clusters were determined by means of the frequency-based UPR approach. This supports the previously outlined hypothesis that the low-frequency cluster A is assignable to interwall cracks and the high-frequency cluster B to cell wall cracks in the tracheids. For the L specimen, the increasing share of $\mathrm{AE}$ events due to the cluster $A_{L}$ seems to correlate with more pronounced crack propagation switching parallel to the grain. For the $\mathrm{R}$ specimen, the shares of AE events of both clusters $A_{R}$ and $\mathrm{B}_{\mathrm{R}}(30 \% / 70 \%)$ correlate with the ratio of the relative crack area of the cell wall crack (67\%) and cell separation (33\%) estimated from the fractographic analysis.

Further insights may be afforded by performing a 3D morphological analysis of SR $\mu \mathrm{CT}$ scans for the evaluation of the deformation at the individual cell scale for the different load states as well as by simulating the AE waves' origin from the damage process and their propagation in the wood materials.

Acknowledgments: The authors acknowledge the financial support of the Swiss National Science Foundation under grant SNF-Project 127134. The authors want to thank the staff of the TOMCAT beamline at SLS in Villigen. Further thanks go to the colleges at the ETH Zürich: S. Ammann, S. Clauss, M.W. Felux, D. Fernandez, P. Hass, O. Kläusler, K. Kránitz, C. Lanvermann, F. Michel, T. Ozyhar, S. Schlegel and F. Wittel for assistance during the measurements and analysis. P. Jenni is acknowledged for manufacturing and assembling the experimental equipment. Thanks to T. Schnider for the help with specimen preparation. Finally, the authors warmly thank Quadrant EPP GmbH for providing the Duratron PAI material.

\section{References}

Ashby, M.F., Easterling, K.E., Harrysson R., Maiti, S.K. (1985) The fracture and toughness of woods. Proc. R. Soc. Lond. A 261-280.

Baensch, F., Sause, M.G.R., Brunner, A.J., Niemz, P. (2015) Damage evolution in wood - pattern recognition based on acoustic emission frequency spectra. Holzforschung 69:357-365.

Cazaux, J., Erre, D., Mouze, D., Patat, J.M., Rondot, S., Sasov, A., Trebbia, P., Zolfaghari, A. (1993) Recent developments in X-ray projection microscopy and X-ray microtomography applied to materials science. J. Phys. III 3:2099-2105.

Chotard, T.J., Smith, A., Bonceur, M.P. Fargeot, D., Gault, C. (2003) Characterisation of early stage calcium aluminate cement 
hydration by combination of non-destructive techniques: acoustic emission and X-ray tomography. J. Eur. Ceram. Soc. 23:2211-2223.

Cousin, W.J. (1978) Young's modulus of hemicellulose as related to moisture content. Wood Sci. Technol. 12:161-167.

Derome, D., Griffa, M., Koebel, M., Carmeliet, J. (2011) Hysteretic swelling of wood at cellular scale probed by phase-contrast X-ray tomography. J. Struct. Biol. 173:180-190.

Eder, M., Jungnikl, K., Burgert, I. (2009) A close-up view of wood structure and properties across a growth ring of Norway spruce (Picea abies [L] Karst.). Trees Struct. Funct. 23:79-84.

Elaqra, H., Godin, N., Peix, G., R'Mili, M.R., Fantozzi, G. (2007) Damage evolution analysis in mortar, during compressive loading using acoustic emission and X-ray tomography: effects of the sand/cement ratio. Cem. Concr. Res. 37:703-713.

Frühmann, K., Burgert, I., Stanzl-Tschegg, S.E. (2003) Detection of the fracture path under tensile loads through in situ tests in an ESEM chamber. Holzforschung 57:326-332.

Forsberg, F., Mooser, R., Arnold, M., Hack, E., Wyss, P. (2008) 3D micro-scale deformations of wood in bending: synchrotron radiation $\mu \mathrm{CT}$ data analyzed with digital volume correlation. J. Struct. Biol. 164:255-262.

Harris, D.O., Tetelman, A.S., Darwish, F.A. (1972) Detection of fiber cracking by acoustic emission. ASTM STP 505:238-249.

Kurz, J.H., Köppel, S., Linzer, L., Schechinger, B., Grosse, C. (2008) Source localization. In: Acoustic Emission Testing in Engineering - Basics and Applications. Eds. Grosse, C., Ohtsu, M. Springer-Verlag, Heidelberg. pp. 108-109.

Lysak, M.V. (1996) Development of the theory of acoustic emission by propagating cracks in terms of fracture mechanics. Eng. Fract. Mech. 55:443-452.

Maire, E., Carmona, V., Courbon, J., Ludwig, W. (2007) Fast X-ray tomography and acoustic emission study of damage in metals during continuous tensile tests. Acta Mater. 55:6806-6815.

Paganin, D., Mayo, S.C., Gureyev, T.E., Miller, P.R., Wilkins, S.W. (2002) Simultaneous phase and amplitude extraction from a single defocused image of a homogeneous object. J. Microsc. 206:33-40.

Radon, J.C., Pollock, A.A. (1972) Acoustic emission and energy transfer during crack propagation. Eng. Fract. Mech. 4: 295-310.

Reiterer, A., Burgert, I., Sinn, G., Tschegg, S. (2002) The radial reinforcement of the wood structure and its implication on mechanical and fracture mechanical properties - a comparison between two tree species. J. Mater. Sci. 37:935-940.
Saavedra Flores, E.I., Friswell, M.I. (2013) Ultrastructural mechanisms of deformation and failure in wood under tension. Int. J. Solids Struct. 50:2050-2060.

Sause, M.G.R. (2010) Identification of Failure Mechanisms in Hybrid Materials Utilizing Pattern Recognition Techniques Applied to Acoustic Emission Signals. Dissertation. ISBN: 978-3-86664889-0. mbv-Verlag, Berlin, pp. 305.

Sause, M.G.R., Gribov, A., Unwin, A.R., Horn, S. (2012a) Pattern recognition approach to identify natural clusters of acoustic emission signals. Pattern Recog. Lett. 33:17-23.

Sause, M.G.R., Müller, T., Horoschenkoff, A., Horn, S. (2012b) Quantification of failure mechanisms in mode-I loading of fiber reinforced plastics utilizing acoustic emission analysis. Compos. Sci. Technol. 72:167-174.

Scruby, C.B. (1985) Quantitative acoustic emission technique. Nondestr. Test. 8:158-159.

Sonderegger, W., Alter, P., Niemz, P. (2008) Investigations on selected properties of tonal wood of spruce from Grisons. Holz Roh Werkst. 66:345-354.

Stampanoni, M., Groso, A., Isenegger, A., Mikuljan, G., Chen, Q., Bertrand, A., Henein, S., Betemps, R., Frommherz, U., Böhler, P., Meister, D., Lange, M., Abela, R. (2006) Trends in synchrotron-based tomographic imaging: the SLS experience. Proc. SPIE 6318:M1-M14.

Stampanoni, M., Groso, A., Isenegger, A., Mikuljan, G., Chen, Q., Meister, D., Lange, M., Betemps, R., Henein, S., Abela, R. (2007) TOMCAT: a beamline for tomographic microscopy and coherent radiology experiments. Synchroton Radiat. Instrum. 879:848-851.

Steppe, K., Cnudde, V., Girard, C., Lemeur, R., Cnudde, J.-P., Jacobs, P. (2004) Use of X-ray computed microtomography for non-invasive determination of wood anatomical characteristics. J. Struct. Biol. 148:11-21.

Trtik, P., Dual, J., Keunecke, D., Mannes, D., Niemz, P., Stähli, P., Kaestner, A., Groso, A., Stampanoni, M. (2007) 3D imaging of microstructure of spruce wood. J. Struct. Biol. 159:46-55.

Van den Bulcke, J., Boone, M., Van Acker, J., Stevens, M., Van Hoorebeke, L. (2009) X-ray tomography as a tool for detailed anatomical analysis. Ann. For. Sci. 66:508-520.

Zauner, M., Keunecke, D., Mokso, R., Stampanoni, M., Niemz, P. (2012) Synchrotron-based tomographic microscopy (SbTM) of wood: development of a testing device and observation of plastic deformation of uniaxially compressed Norway spruce specimens. Holzforschung 66:973-979. 